\title{
Telemedicine: History and Success Story of Remote Surgical Education in India
}

\author{
Sanjay Kumar Yadav ${ }^{1}$. Anjali Mishra ${ }^{2} \cdot$ Saroj Kanta Mishra ${ }^{2}$
}

Received: 12 June 2021 / Accepted: 19 June 2021 /Published online: 8 July 2021

(c) Association of Surgeons of India 2021

\begin{abstract}
Initiation of telemedicine in medical education in India was at par with developed countries but acceptance and progress have been slow. However, the recent coronavirus disease-19 (COVID-19) pandemic leading to disruption of Halstedian model of surgical teaching has changed the traditional dynamics of perception of this mode of education. Sanjay Gandhi PostGraduate Institute of Medical Sciences (SGPGIMS), has been a pioneer and introduced the telemedicine system into surgical education as early as in year 2001. In this article, we reviewed the literature on tele-education in surgical field in Indian scenario, with particular emphasis on tele-education activities at the SGPGIMS, with respect to current thinking and future prospects on surgical training.
\end{abstract}

\section{Introduction}

Apprenticeship model or Halstedian model of surgical education and training, where the learner imitates the actions of a skilled mentor, has been the gold standard of imparting surgical education for over a century [1]. Although effective, this model requires learners to be exposed to a large number of surgeries performed by a limited number of dedicated teaching faculty, onsite presence of the trainee, and long years of training [2]. More often than not, even after successful completion of training, the trainee still needs more experience for some skill refinement and enhancement through new avenues such as conferences, workshops, and short-term observer-ships which may involve costly travel and stay. In a low and middle country like India, this leads to shortage of skilled surgeons in remote areas [3]. Another recent phenomena which has changed the traditional dynamics of training is the ongoing COVID-19 pandemic causing disruption of "live" surgical teaching and surgical educators promptly rose to the challenge with e-teaching [4]. Information and Communication Technology (ICT)-based tools are

Saroj Kanta Mishra

skmishra@sgpgi.ac.in; skmishra_1956@yahoo.com

1 Department of Surgery, NSCB Medical College, Jabalpur, India

2 Department of Endocrine Surgery, Sanjay Gandhi Postgraduate Institute of Medical Sciences, Raebareli Road, Lucknow, India 226014 bridging the gap created by the pandemic regardless of the socio-economic status of a country. A model which is now getting all the attention, acceptance from previous sceptics and critics, because of a ravaging pandemic was envisioned, established and has been utilized in imparting surgical education since two decades at Sanjay Gandhi Post Graduate Institute of Medical Sciences, Lucknow (SGPGIMS). In this article, we reviewed the literature on tele-education in surgical field in India, described tele-education activities at the SGPGIMS, with respect to current thinking and future prospects on surgical training.

\section{Methods}

\section{Literature Review}

This review of telemedicine in surgical education was conducted according to the PRISMA-ScR (Preferred Reporting Items for Systematic reviews and Meta-Analyses extension for Scoping Reviews) protocol. The PubMed database was searched for relevant literature until May 15, 2021. The search strategy included terms related to telemedicine and it's synonyms ("telemedicine" OR "e-health"OR "m-health" OR "email" OR "electronic mail" OR "telephone" OR "mobile phone" OR "cell phone" OR "video conference"), tele-education and its synonyms ("tele education" OR "distance education" OR "remote education" OR "distance learning") and India. Apart from scholarly/published 
material, hand-searching of google scholar, google, and grey literature search was also performed.

The articles reporting the use of ICT in imparting education in general surgery or its subspecialties were included in the review. Our aim was to evaluate the use of ICT tools in surgery in India and no attempt was made to assess the quality of the papers.

\section{Results and Discussion}

The initial search yielded a total of 143 studies, out of which four were found to be duplicate. Based on title and abstract, 123 studies were excluded as they did not fulfill the inclusion criteria. Full texts of remaining 16 studies were analyzed and 7 studies matching with pre-defined criteria were evaluated in this review (Fig. 1). Five articles reporting on surgical training and education were from SGPGIMS and have been discussed under tele-surgical education at SGPGIMS section. Two articles reported tele-education experience in surgery from All India Institute of Medical Sciences (AIIMS), New Delhi, and Guwahati Comprehensive Cleft Care Centre (GCCCC), Assam.

Initial use of ICT tools for medical education in India was mostly utilized by medical branches [5-7]. Based on our literature search, only few centers utilized telemedicine facilities to impart surgical education. Telemedicine facility at AIIMS, New Delhi, was started in January 2006 and utilized this in neurosurgical education. Cadaveric dissection of endoscopic transsphenoidal dissections and various surgical approaches are captured by advanced cameras and transmitted to various peripheral centers across India. Telemedicine facility has helped them to deliver the core neurosurgical teaching to more than 500 neurosurgeons across India, leading to dissemination of knowledge to peripheral centers [8]. Similarly, the GCCCC has an interactive live surgery model offering several advantages over the traditional operating theater learning. First, this model can accommodate many observers without increasing the number of people in the operating room. Clinical flow is not disrupted, and audiovisual specialists are tasked with all the broadcast logistics greatly increasing the efficiency of knowledge transfer [9].

\section{Tele-surgical Education at SGPGIMS}

\section{Background}

The School of Telemedicine \& Biomedical Informatics (STBMI) was established by the SGPGIMS with the financial support of the Government of Uttar Pradesh and
Fig. 1 Flow chart summarizing the results of the screening process and study selection as per the PRISMA guideline
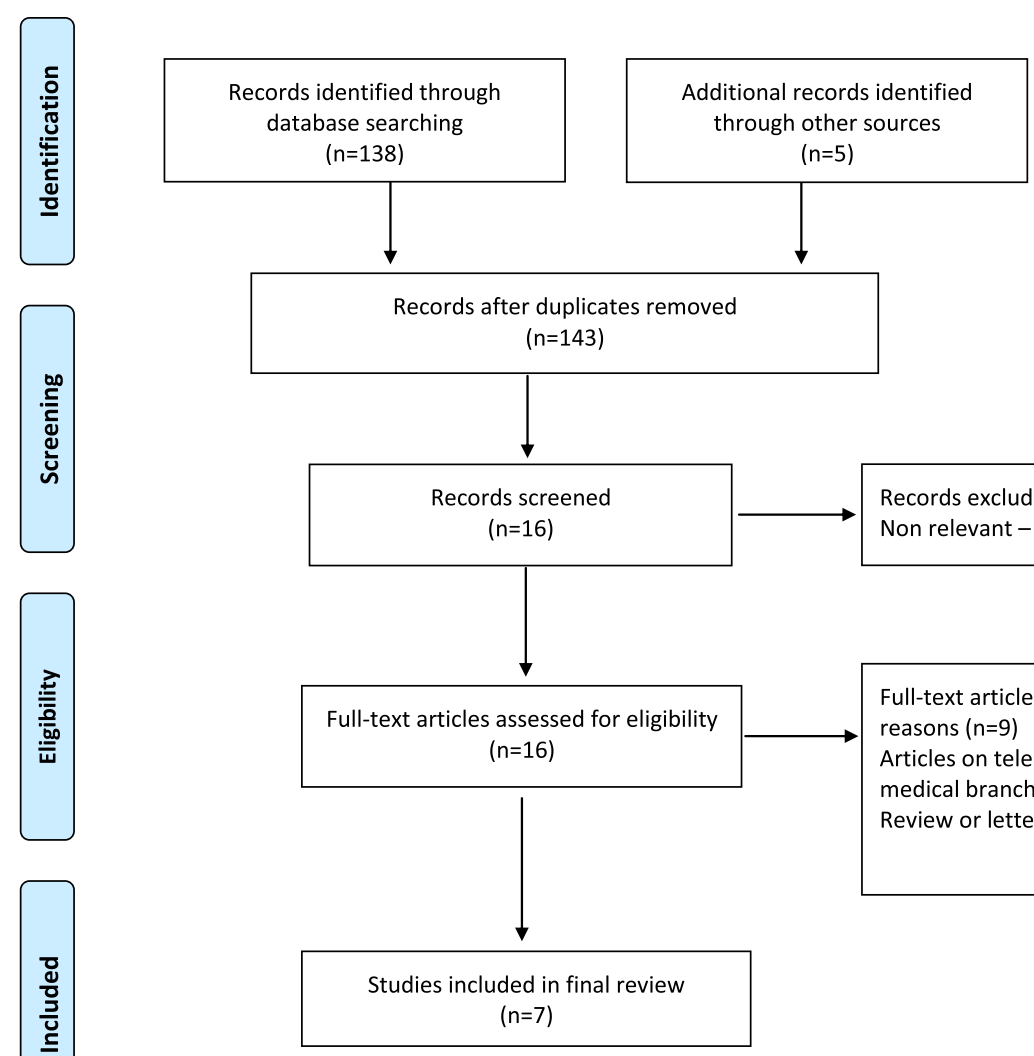

Records excluded $(n=127)$

Non relevant -127

Full-text articles excluded, with reasons $(n=9)$

Articles on tele-education in medical branches- 5

Review or letter to editor articles - 4 
Ministry of Communication \& Information Technology, Government of India with the objective of creating human resources in various fields of healthcare information technology. This is the first academic institution of its kind dedicated exclusively to the health care informatics in a public funded setup. The SGPGIMS distance medical education program began in September 2001 by networking with Sriram Chandra Bhanj Medical College (SCBMC) in Cuttack, Orissa, located $1500 \mathrm{~km}$ away on the eastern coast of India. With basic telemedicine infrastructure at both ends and $128 \mathrm{Kbps}$ bandwidth using Integrated Services Digital Network (ISDN), this program focused mainly on the postgraduate medical students [10]. The same system was later utilized for tele-follow up and pre-referral counseling sessions [11]. After the success of this program, the Orissa state government with the support of Indian Research Space Organisation (ISRO) provided permanent satellite communication links for point-to-point connectivity with Demand Assigned Multiple Access Very Small Aperture Terminal of $384 \mathrm{Kbps}$ bandwidth to all the three state medical colleges, along with an advanced videoconferencing platform in March 2003 [12].

\section{Post Graduate Surgical Education}

Initial tele-education activities were started by four departments of SGPGIMS out of which two were surgical departments (Endocrine Surgery and Gastrointestinal Surgery) with Amrita Institute of Medical Sciences (AIMS), Kochi in March 2004 [12]. Endocrine surgery department has been holding regular teaching sessions with Christian Medical College Vellore (CMC), AIMS Kochi, SCBMC Cuttack, King George University (KGMU) Lucknow. These sessions include presentations of rare cases, surgical challenges, case discussions, and surgical audits, in collaboration with endocrinologists, nuclear physicians, and pathologists, thus richly enriching the learning of all those involved. Subsequently, the Department of Urology too started virtual clinical grand round with their peers in two premier institutions of the country, AIIMS, New Delhi, and the Postgraduate Institute of Medical Education and Research (PGIMER), Chandigarh. Later, Clinico-pathology conferences (CPC) with PGIMER became a regular activity. Institution-combined grand round (CGR) conducted at SGPGIMS is shared with multiple centers including those some of the non-teaching institutes and hospitals. These educational activities helped in shaping the current era of tele-education for post graduate medical students.

\section{Tele-mentoring}

The first successful tele-mentoring experiment was carried out in 2004 when a parathyroid surgery was performed under expert guidance from SGPGIMS. Patient had two previous unsuccessful attempts at tumor removal by the same surgeon at AIMS, Kochi. This experiment was the first of its kind reported from India where a more experienced endocrine surgeon at SGPGIMS guided in successful intra-operative tumor localization and removal via telemedicine [13].

Another success story of tele-mentoring was shown when two general surgeons at SCBMC, Cuttack, were tele-mentored from SGPGIMS, using ICT tools to develop Endocrine Surgery. Two faculty members from SCBMC, Cuttack, did a short 3-month training course in endocrine surgery at SGPGIMS and after completion, Tele-mentoring was introduced as a reinforcement method for continuing training and skills development [14]. Based on the quantum, safety, and quality outcome of endocrine surgeries, the state government approved creation of a super-speciality department of endocrine surgery in Cuttack. This proved that sustained engagement using tele-mentoring can transfer surgical skills to needy surgeons and enable them to match the expertise of mentors [15].

\section{Knowledge Sharing and Professional Growth Using Telemedicine}

First international telesurgery conference was organized by SGPGIMS in 2001. Since then, multiple conferences, symposia, seminars, and surgical workshops have been organized. Faculty from the best of the international and national institute which sometimes could not come to India due to logistic issues have participated live in these events. Similarly, many remote participants have benefitted by participating in cyber surgical workshops conducted by SGPGIMS which have been transmitted to various medical colleges in India and African countries. With current state of art technology, the participants experience telepresence akin to watching surgery inside the operation room. An audit of endocrine surgery knowledge sharing via telemedicine showed that $80 \%$ of participants felt that the technology helped in learning new things and strengthening relations with peers, whereas $>90 \%$ were of the view that it helped in knowledge exchange and development of skills as well as was helpful in supporting clinical decisions [16].

\section{National Knowledge Network}

The Ministry of Health, Govt. of India, started interlinking medical colleges across the country via a National Medical College Network (NMCN) for common e-Education [17]. STBMI at SGPGIMS is the national resource center. Highspeed optic fiber-based internet bandwidth has been created under National Knowledge Network (NKN) Project in 150 medical colleges. NKN is a state-of-art countrywide network to interconnect all institutions of higher learning and 
research with a high-speed data communication network to facilitate knowledge sharing and collaborative research [17]. Many medical institutions have migrated to NKN backbone to enhance their capacity of telemedicine activities. Fifty medical colleges were connected in phase 1 . These colleges now share countrywide virtual classroom where teachers and students can interact in real time and more than 6493 tele sessions have been carried out so far. This has also enabled collaborative research and sharing of virtual library.

\section{Challenges and Future}

Information and Communication Technology is growing exponentially. Bharat Broadband Network Limited (BharatNet) is an Indian government-owned telecom infrastructure provider, for the establishment, management, and operation of the national optical fiber network to provide a minimum of $100 \mathrm{Mbit} / \mathrm{s}$ broadband connectivity to all 250,000 - gram panchayats in the country; when complete, this could truly transform telemedicine delivery across India. This is the time to utilize this transformative tele-healthcare technology in imparting surgical education as well.

Another new frontier is the real-time audio-visual mentoring tool for complex robotics and telesurgery. The world's first transoceanic operation (robotic cholecystectomy) on human over high-speed fiberoptic connection was performed by surgeons in New York and patient in Strasbourg, France [19]. As the transfer of technology is becoming fast-paced in increasing globalization, day is not far when we will be witnessing such surgeries in India. Technology will enable real-time remote mentoring as well [20]. Role of virtual reality in imparting surgical training is increasing in western countries. Virtual Interactive Presence and Augmented Reality (VIPAR) is a recently developed technology that allows surgeons to deliver real-time virtual assistance, allowing the remote surgeon to be able to digitally reach into the operating field, delineate anatomy, and provide a visual demonstration.

of complex surgical techniques [21].

Despite increasing presence and acceptance of ICT tools in surgical education, most institutes in India employ it only in project mode. Very few medical colleges/institutes such as SGPGIMS, Lucknow, AIMS, Kochi, Christian Medical College, Vellore, PGIMER, Chandigarh, and AIIMS, New Delhi, have now integrated this into their routine educational programs. As the smartphones and gadgets are becoming more and more affordable, videoconferencing through mobiles, using $4 \mathrm{G}$ is on the anvil and will play a major role in tele-education. The ongoing COVID-19 pandemic has affected the training of surgical residents in adverse way, but because of shear necessity, it has resulted in integration and acceptance of telemedicine into the formal education and training [22, 23]. Ministry of Health, Government of India, released telemedicine practice guidelines on March 25, 2020 [24]. Subsequently, National Medical Commission issued guidelines for virtual conduct of postgraduate practical exit examination where virtual presence of external examiners is allowed [25].

In contrast to rapid scale adoption of tele-education in medical specialties, the same has not been experienced in surgical domains. One of the major challenges is that surgical education mostly focuses on skill acquisition for which the students like to get engaged with a surgeon while performing a procedure which is not accessible from close quarters unless one is specializing in surgical subjects. In the undergraduate years, the groups of students are made to watch the procedure from operation theater gallery which does not serve the purpose. We need to integrate interactive audio-video system in the operation theaters to be able to demonstrate the surgical skill to students across their locations on their smart phones, handheld devices, or computers. Another barrier pertains to the lack of policy. The regulatory agency controlling medical education need to approve electronic way of delivering surgical skill demonstration, addressing ethical issues concerning live demonstration of surgical procedures, introducing consent allowing patient's approval. Simultaneously, tele-mentoring and tele-monitoring of surgical skills should find a place in skill assessment and training/retraining remotely. In a country like our financial constraints in developing digital operation, theaters/ interventional suites is also a hindrance.

To conclude, the role of telemedicine in surgical education and training is promising. Advances in technology will allow for greater visualization capabilities such as $3 \mathrm{D}$ tele-surgical viewing and virtual presence leading to surgeons digitally reach into operating fields and impart training. A developing country like India stands to benefit in terms of both patient care and medical education whereby low-cost health care and standard training can be provided using ICT tools in coming decades. We propose here to integrate telemedicine within the framework of routine medical education.

Author Contribution Sanjay Kumar Yadav-literature search, figures, study design, data collection, data analysis, data interpretation, and writing. Anjali Mishra and Saroj Kanta Mishra—revision and editing of the manuscript.

This is to declare that all authors have contributed to the study. No part of the manuscript has been sent for consideration elsewhere or published in any international or national journal. The authors clearly certify that there is no aspect of plagiarism. All the conflicts of interest have been clearly defined and the source of grant disclosed. Due ethical permission/consent have been obtained for carrying out the study. In case of any dispute, the authors will be held fully responsible for the statement disclosed in the cover letter. The authors are also aware of the 
copyright rules and declare that they will not reproduce any published text without due permission from the journal.

\section{Declarations}

Ethics Approval Not Applicable. All procedures performed in studies involving human participants were in accordance with the ethical standards of the institutional and/or national research committee and with the 1964 Helsinki declaration and its later amendments or comparable ethical standards.

Competing Interests The authors declare no competing interests.

\section{References}

1. Walter AJ (2006) Surgical education for the twenty-first century: beyond the apprentice model. Obstet Gynecol Clin North Am 33(2):233-6, vii. https://doi.org/10.1016/j.ogc.2006.01.003

2. Numanoglu A (2017) Using telemedicine to teach paediatric surgery in resource-limited countries. Pediatr Surg Int 33(4):471474. https://doi.org/10.1007/s00383-016-4051-6

3. Sharma DC (2015) India still struggles with rural doctor shortages. Lancet 386(10011):2381-2382. https://doi.org/10.1016/ S0140-6736(15)01231-3

4. Agrawal V, Sharma D (2020) Surgical training "Before COVID-19 (BC)" to "after COVID-19 (AC)": needs-driven approach for the Global South. Br J Surg 107(12):e585-e586. https://doi.org/10. 1002/bjs. 12022

5. Ganapathy K (2014) Telehealth in India: the Apollo contribution and an overview. Apollo Med. https://doi.org/10.1016/j.apme. 2014.07.014

6. Mahadevan S, Muralidhar K, Shetty D (2012) Tele-education service using telemedicine network in healthcare industry. Telemed J E Health 18(9):699-702. https://doi.org/10.1089/tmj.2011.0278

7. Ramkumar V, Selvakumar K (2016) Telemedicine in a tertiary care hospital in South India- a thirteen year review. J Int Soc Telemed EHealth 4:e29 (1-6)

8. Meher S, Kurwal NS, Suri A (2017) E-learning through telemedicine in neurosurgical teaching and patient care. Int J Telemed Clin Pract 2(1):2-11. https://doi.org/10.1504/IJTMCP.2017.082099

9. Nagengast ES, Ramos MS, Sarma H, Deshpande G, Hatcher K, Magee WP Jr, Campbell A (2014) Surgical education through video broadcasting. J Craniofac Surg 25(5):1619-1621. https:// doi.org/10.1097/SCS.0000000000001143

10. Mahapatra AK, Mishra SK, Kapoor L, Singh IP (2009) Critical issues in medical education and the implications for telemedicine technology. Telemed J E Health 15(6):592-6. https://doi.org/10. 1089/tmj.2009.0057

11. Mishra A, Kapoor L, Mishra SK (2009) Post-operative care through tele follow-up visits in patients undergoing thyroidectomy and parathyroidectomy in a resource crunch environment. $\mathrm{J}$ Telemed Telecare 15(2):73-6

12. Singh K, Mishra SK, Misra R, Gujral RB, Gupta RK, Misra UK, Ayyagari A, Basnet R, Mohanty BN (2004) Strengthening postgraduate medical education in peripheral medical colleges through telemedicine. Telemed E Health 10:S55-S56

13. Pradeep PV, Mishra SK, Vaidyanathan S et al (2006) Telementoring in endocrine surgery: preliminary Indian experience. Telemed J E Health 12:73-77

14. Pradeep PV, Mishra A, Mohanty BN, Mohapatra KC, Agarwal G, Mishra SK (2007) Reinforcement of endocrine surgery training: impact of telemedicine technology in a developing country context. World J Surg 31(8):1665-1671. https://doi.org/10.1007/ s00268-007-9108-1

15. Yadav S, Mishra S, Mohanty A, Mohanty B, Mishra A (2018) Bridging the gap of skilled surgeons in low and middle income countries using ICT based tools: a case study in super-speciality training. J Int Soc Telemed EHealth 6(1):e22. https://doi.org/10. 29086/JISfTeH.6.e22 (1-6)

16. Agrawal R, Mishra SK, Mishra A, Chand G, Agarwal G, Agarwal A, Verma AK (2014) Role of telemedicine technology in endocrine surgery knowledge sharing. Telemed J E Health 20(9):868874. https://doi.org/10.1089/tmj.2013.0164

17. National Telemedicine Portal. Available from: http://nmcn.in/. Accessed 15 May 2021

18. National Knowledge Netwrok, Govt of India. Available from: https://www.nic.in/nkn. Accessed 15 May 2021

19. Marescaux J, Leroy J, Rubino F et al (2002) Transcontinental robot-assisted remote telesurgery: feasibility and potential applications. Ann Surg 235(4):487-492. https://doi.org/10.1097/00000 658-200204000-00005

20. Lee JH, Tanaka E, Woo Y, Ali G, Son T, Kim HI, Hyung WJ (2017) Advanced real-time multi-display educational system (ARMES): an innovative real-time audiovisual mentoring tool for complex robotic surgery. J Surg Oncol 116(7):894-897. https:// doi.org/10.1002/jso.24722

21. Davis MC, Can DD, Pindrik J et al (2016) Virtual interactive presence in global surgical education: international collaboration through augmented reality. World Neurosurg 86:103e111. https:// doi.org/10.1016/j.wneu.2015.08.053

22. Buitendijk S, Ward H, Shimshon G, Sam AH, Sharma D, Harris M (2020) COVID-19: an opportunity to rethink global cooperation in higher education and research. BMJ Glob Health 5(7):e002790. https://doi.org/10.1136/bmjgh-2020-002790

23. Agrawal V, Yadav SK, Agarwal P et al (2020) "GRASP" Module of self-assessment with virtual mentoring for uninterrupted surgical training during COVID-19 pandemic. Indian J Surg 82:13341335. https://doi.org/10.1007/s12262-020-02613-0

24. Board of Governors, In supersession of the Medical Council of India- Telemedicine practice guidelines, 25 March 2020. Available from: https://www.mohfw.gov.in/pdf/Telemedicine. pdf. Accessed 15 May 2021

25. National Medical Commission, Post graduate medical education board advisory, 22 April 2021. Available from: https://www.nmc. org.in/MCIRest/open/getDocument?path=/Documents/Public/ Portal/LatestNews/22-4-2021.pdf. Accessed 15 May 2021

Publisher's Note Springer Nature remains neutral with regard to jurisdictional claims in published maps and institutional affiliations. 